\title{
Natural Mechanisms and Methods of Protection against Coronavirus COVID-19
}

\section{Evgeny Bryndin}

Research Department of Research Centre "NATURE INFORMATIC" of Technological Platform Future Medicine, Novosibirsk, Russia. Corresponding Author: Evgeny Bryndin, Research Department of Research Centre "NATURE INFORMATIC" of Technological Platform Future Medicine, Novosibirsk, Russia.

Received date: January 20, 2021; Accepted date: February 12, 2021; Published date: February 15, 2021

Citation: E Bryndin. (2021) Natural Mechanisms and Methods of Protection against Coronavirus COVID-19. Journal of Clinical and Laboratory Research;2(1); DOI:10.31579/2768-0487/002

Copyright: () 2021, Evgeny Bryndin, This is an open access article distributed under the Creative Commons Attribution License, which permits unrestricted use, distribution, and reproduction in any medium, provided the original work is properly cited.

\begin{abstract}
Our planet is a living creature that has its own protective viral mechanism. Viruses are activated when people too zealously intervene in the natural processes on the planet and worsen the environment. With a decrease in the spiritual level of society, a deterioration in ecology, climate change, a decrease in the frequency of the Schumann resonator supporting the energy healthy state of the body, pollution of water and soil and other catastrophic disorders of natural processes on the planet, an epidemic and the process of mutation of viruses begins, as a result of which more and more of their species appear. For the people will rise against the people and the kingdom against the kingdom; and there will be earthquakes in places, and there will be smoothness and turmoil. This is the beginning of Mark's disease (13:8). The article discusses natural mechanisms and methods of protection against coronavirus.
\end{abstract}

Keywords: coronavirus COVID-19; resonant method of detection, mechanisms and methods of protection

\section{Introduction}

The main source of human infection with coronavirus is bats. They themselves do not suffer from this infection, because they are able to raise body temperature, thereby activating the immune system. The litter of bats exudes fumes that penetrate the human body. Litter pairs can lead to the development of serious pathologies of the respiratory system.

Virologist Jonathan Latham and biologist Allison Wilson found notes from a doctor who in 2012 treated miners from the Chinese province of Yunnan. The notes describe how workers cleaned the mine from bat feces for two weeks, and then fell ill with a strange disease. Sick workers showed symptoms characteristic of COVID-19, high fever, dry cough and pain in the limbs. They were treated, as infected patients are now treated with coronavirus, with the help of anticoagulants, antibiotics and ventilators. As a result, three of the six workers died.

Bats are in all countries. They were a global source of human coronavirus infection. That is, they were the source of the pandemic.

The article discusses the mechanisms and methods of reproduction of coronavirus, its detection and protection against coronavirus.

\section{Mechanism of coronavirus reproduction in the body and infection pathway}

Viruses have no cellular structure. Viruses are intracellular parasites, and outside the cell they do not show any living properties (do not grow, do not feed, do not produce energy, they do not have metabolism). They have heredity and variability and are able to reproduce similar forms, that is, reproduce. They consist of genetic material (RNA or DNA) enclosed in a protein envelope called capsid. A separate viral particle - a virion, consists of one nucleic acid molecule covered with a shell of a small number of protein molecules. After entering the cell, the virus changes its metabolism, directing all cell activity to the production of viral nucleic acid and viral proteins. Inside the cell, viral particles are assembled from synthesized nucleic acid molecules and proteins. Until the death in the cell, a huge number of viral particles have time to be synthesized. Ultimately, the cell dies, its shell bursts, and viruses exit the host cell. A cell infected with coronavirus 2019-nCoV capable of producing thousands of carriers of new viral particles. The 2019-nCoV virus is extremely active and each cell creates thousands of new coronavirus carriers that are released from the surface of the affected cell and infect other cells. Coronavirus SARS-CoV-2, which causes COVID-19 disease, multiplies in the human body in the lungs, upper airways and intestines.

The ways of spreading viruses are: air-drop (coughing, sneezing), through body fluids (blood, sperm and saliva), from skin to skin (with touches and handshakes), from skin to products (when touching food with dirty hands, viruses can get into the intestines). Once in the body, the virus attaches to the membrane of a foreign cell.

\section{Detection of coronavirus COVID-19 in the body by resonance technology}

Coronavirus COVID 19 lay on the human population. Hundreds of thousands of people in the world get infected every day. The rapid detection of coronavirus in every person on the planet earth is a pressing problem.

The NATURAL INFORMATICS Research Center is developing a technology for detecting coronavirus COVID-19 in the body by a resonance method. The development represents Know-How. The 
detection of coronavirus COVID-19 in the body can be carried out by a micro-device consisting of a microresonator for detecting coronavirus in the body based on resonance at its own frequency of electromagnetic waves of the biofield, and from a microprocessor for notifying a citizen's disease to a network medical platform. There is a technology for making optical microresonators with an accuracy of 0.17 angstrom [1]. The size error of the microresonators is less than the diameter of the hydrogen atom. The ability to create simple microresonators with an accuracy of 0.17 angstrom allows them to be used to detect each person's coronovirus [2-4]. Such a significant leap in microresonator and artificial intelligence technologies allows them to be used to detect coronavirus in infected people anywhere on the planet.

The design of the micro-device is in the form of an amulet. An amulet with a micro device is assigned a number in a network medical platform. A sensitive micro device for detecting coronovirus COVID-19 in the body provides detection of infected people throughout the world through the World Health Organization's international medical platform. The international medical platform for identifying the amulet number with the host and a micro device for detecting coronovirus COVID-19 in the body will help eliminate the presence of infected patients at all objects of mass accumulation of people in all points of the world in open and closed areas and premises. This requires legislation to require citizens to wear an amulet with a micro coronavirus detection device. An amulet with a micro device is worn from the chest at the level of the thymus gland. The technology provides rapid detection of people infected with coronavirus, helps in their neutralization from public places and, thereby, does not spread coronavirus.

\section{Natural bioenergy methods to protect against coronavirus}

\subsection{Vaccination against coronavirus with injections}

Vaccination of the population against coronavirus increases collective immunity. The vaccine can be live (weakened virus), inactivated (dead virus) or vector - precisely such vaccines for coronavirus. They contain a harmless adenovirus for humans, in the DNA of which the coronavirus gene is located. Adenovirus is then used as a delivery container.

Any vaccine contains a specific antigen - a protein that provokes the production of antibodies - the immune response. In the body, antigen is met by specially adapted cells - macrophages. They get acquainted with the antigen and read information from it. They transmit the obtained information to T-lymphocytes, they in turn begin to change, and among them cells appear that will also participate in the immune process. T cells transmit information to B lymphocytes, which are converted into plasma cells capable of producing antibodies. Part of B lymphocytes turns into memory cells. They store information about the antigen and, upon reencounter with a similar antigen, trigger an immune response (antibody formation) in a shorter time frame.

The immune system is customized by hardening of an organism on air and in water. It is previously necessary to customize the system of a thermoregulation. Hardening of an organism for control of immune system with emotional fixing is carried out no more than a month not to break balance of inhibition and exaltation of a nervous system and not to narrow the capillaries feeding organism cells (Figure 1).

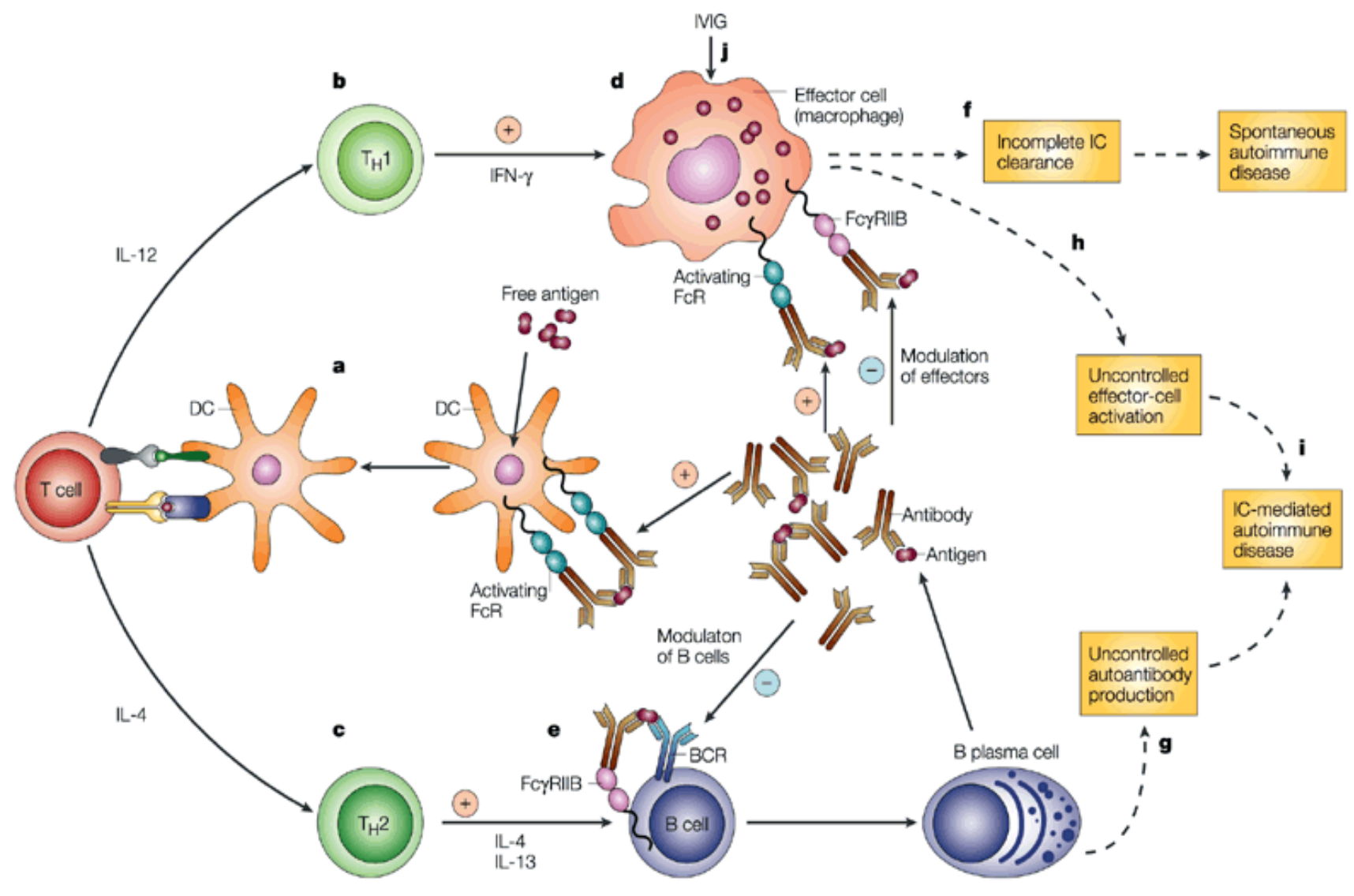

Nature Reviews | Immunology 
The good health has to be result of control.

\subsection{Protection against coronavirus by ether field and biofield}

The main immunity is a strong ethereal field. The silver-bluish ethereal field, the field of life, permeates our physical body, every organ, system, every cell. It ensures integrity and vitality, reflects the state of the physical body and life systems, serves as a conductor and regulator of life energy, as well as a repository of life forces and clean energy of life. The state of the ethereal field as a whole, a person feels like the level of his vitality, energy, cheerfulness, tone, immunity.

In the ether field, energy flows through channels and meridians. It is necessary to clean and work on the ether field so that it is dense. The blocks and clamps that arise in it, if possible, must be immediately identified and neutralized, and the energy flow restored. It is also necessary to clean and keep clean the energy filling it. Contaminates and reduces the density of the ether field:

- Excessive stress in the physical body interfering with the flow of energy.

- Fuss, waste of energy.

- Negative emotions and desires.

- Negative thoughts and attitudes.

- Improper breathing: not rhythmic breathing, mouth breathing,

etc.

- Improper power supply.

- Alcohol, tobacco, etc.

- Contamination of the physical body.

- No contact with nature and fresh air and the sun.

- Wasteland.

The purity and density of the ether field retains:

- Maintaining a smooth, harmonious and balanced energy flow.

- Positive feelings.

- Purity of thoughts, attitudes.

- Staying in inner peace.

- Keeping the body in tone.

- Proper nutrition. Drink clean water.

- Cleansing the physical body in the sauna.

- Physical activity.

- Hardening with contrast shower.

- Massage helps normalize the flow of energy in the body.

- Outdoors and sunshine.

- Life activity in harmony with the surrounding world.

- Correct day mode. Rest, sleep.

The density of the ethereal field determines the state of a person: 0-5\% (almost no biofield) - weakness, paralysis, death.

$5-20 \%$ - ailments, very frequent diseases.

$20-30 \%$ is a good body condition, but often fatigue.

$30-50 \%$ - good health, cheer, stamina.

$50-70 \%$ is an excellent state of health.

$70-100 \%$ is a very dense biofield. Good health!

The denser it is, the healthier a person is. The strongest and densest air field that a person is able to develop on his own is $100 \%$. If a person has an etheric field with a density of $60 \%$ or more, then the coronavirus will bypass it. Thanks to the density of the field, he will just slip and walk by. If the coronavirus breaks into a person with a dense ether field from $30 \%$ to $60 \%$, then the chance of healing will be quite high, $60-70 \%$.

There are a certain group of individuals who do not get sick when in repeated contact with patients with coronavirus, who are its excretors. This group of people has more biofield energy than coronavirus biofield energy. The great energy of biopolitics in people with a righteous good spirit [5-7].

\subsection{Protection against coronavirus infection}

1. Medical mask. To a certain extent, it protects us from the virus entering the airway - but only a certain time - until it gets wet from your breath. Then viruses will be able to penetrate the nasal cavity through the wet capillaries of the mask - although not in such an amount. So if you use a mask, change it every 1.5 hours. And only a respiratory agent can significantly block the access of viruses to your body - but in everyday life this is little real. However, in the midst of an epidemic, it is better to wear a regular mask than to be near the carrier of the virus without it - just change it regularly.

2. Wash your hands more often. This simple rule allows you to remove most of the viruses that stuck to your palms when contacting ATMs, door handles, railings, elevator buttons, etc. After each touch of a potentially infected surface, simply wash your hands with soap and warm water, wiping each finger. How does soap affect coronavirus Sars-CoV-2 and most other viruses? In short, it destroys the lipid bilayer that covers this microbe. Soap breaks up the fat membrane, and without it the virus breaks down into pieces. Well, then, even if the soap doesn't break the membrane of viruses, they'll just wash the soap water into the sink. So that frequent use does not destroy the natural fat film protecting against harmful bacteria, choose a solid hypoallergenic soap with a neutral $\mathrm{Ph}$ and with an age mark of $0+$. Wash your hands only after contact with potentially infected items.

3. Avoid crowding. If this cannot be avoided, then try to keep your distance. If you can stay at home and not go where there are many people (concert, cinema, market, nightclub), then do not go. It is better to avoid the crowd and do not approach outsiders on the street - observe a distance of at least a meter.

\section{During the epidemic of handshakes, hugging and kissing.}

5. With the inevitable reduction of distance with strangers (especially coughers), turn away and hold your breath for 5-6 seconds, and when the distance breaks, take an energetic exhalation through the nose, cleaning the airways. Take three vigorous exhalations through the nose and two through the mouth, cleaning the lungs, trachea and bronchi from adhering viral particles. To more vigorously exhale and clear the airways of viruses, connect the diaphragm, straining the muscles of the abdominal press.

6. Rinse your nose with saline. Saline is a $0.9 \%$ solution of $\mathrm{NaCl}$ (table salt). A very effective procedure invented by Indian yogis a few millennia ago. Pharmacies have various devices and sprays for this purpose. If you prepare the solution yourself, it is better to use sea salt or salt enriched with $\mathrm{KCl}$ and $\mathrm{Mg}$ (in grocery stores it is sold under the brand name "Salt with reduced sodium content"). But in principle, ordinary food salt, which is in any house, will be suitable. Take about 2 grams of salt on a glass of warm water, stir and wash your nose with this solution.

7. Use protective gloves. In crowded places, where you have to touch surfaces (transport, shops, hospitals) it is advisable to use gloves. It is better to use conventional non-sterile rubber gloves, and if they are not available, then any technical fabric analogues. If you use dress gloves, 
change them daily, wash them thoroughly in disinfectants, and smooth them with a hot iron.

8. Do not touch staircase railings, desks, other people's gadgets, toys and public doors. If possible, open and close the doors using elbows or shoulders. If you did this without gloves, be sure to wash your hands after each such contact. Using ATMs, wipe your hands with wet napkins. To reduce the risk of coronavirus infection in the elevator (both from contact with infected people and when touching the elevator buttons) - move along the stairs on foot. If you need to climb to 4-5 floors, or go down from 5-6 - definitely go up the stairs. And reduce the risk of infection in the elevator, and strengthen your cardiovascular and musculoskeletal systems. Move for years and heart attacks and osteoporosis.

\section{Brush your teeth in the morning and in the evening.}

\section{Disinfection of the room with antiseptics.}

\section{Use personal cutlery and utensils.}

12. Strengthen cellular immunity. A healthy adult will be able to provide the body with vitamins and strengthen immunity. Vitamin D is found in fish oil, salmon, cod liver, egg yolk and dairy products. Vitamins B2, B6, B12 are found in milk, eggs, cereals, legumes, nuts, seafood. Vitamin E contains nuts, seeds, vegetable oils and seafood. Vitamin C contains rosehips, pomegranate, green tea, fermented cabbage, citrus fruits, currants and pepper. Vitamin A contains carrots, milk, eggs, butter, cheese and hawthorn.

13. Walk outdoors away from people. At the same time, you can not only slowly walk along the alleys of the park, but from time to time practice fast walking or jogging. Such activity not only allows you to better clear the lungs from the infection, but also stimulates immune surveillance cells that can find and neutralize harmful bacteria and viruses.

14. On the street, do not touch the face, do not touch the eyes and mucosa of the mouth and nose.

\section{Conclusion}

Mankind leads to nature, resources and the living earth as barbarians. According to spiritual laws, it deservedly received a coronavirus for its deeds. If mankind does not build a moral spiritual way of life, nature will attack it with disasters. If humanity does not restore the environment and provide sanitation to public places, nature will attack it with coronaviruses. A person with the ability to experience spiritual needs more accurately and better perceives the world around him in all his diversity and seeks to preserve him. Spiritual values express the social nature of man himself and the conditions of his existence. God created the earth and is its master. He divided mankind into peoples and gave the resources of the earth to them in management for life and development. So that they learn from each other and take on the best achievements and live in peace and love. For love to become the driving force of every man, God gave the nations a New Testament for the mind and heart, and for man to have a righteous mind and good heart, create for the benefit of all mankind and did not destroy the earth.

\section{References}

1. N. A. Toropov and M. Sumetsky. (2016) Permanent matching of coupled optical bottle resonators with better than $0.16 \mathrm{GHz}$ precision. Optics Letters, Vol. 41, Issue 10, pp. 2278-2281.

2. Evgeniy Bryndin. (2020) Vibration approach to coronavirus detection and neutralization COVID-19. American Journal of Laboratory Medicine, Volume 5, Issue 4, pp. 113-117.

3. Evgeniy Bryndin. (2020) Resonance approach of detection and neutralization COVID-19. Japan Journal of Medical Science, Volume 1, Issue 2, pp.11-15.

4. Evgeniy Bryndin. (2020) Implementation of International Telemedicine network with Rapid Coronavirus Registration by Resonant Technology to Neutralize the Pandemic. Computational Biology and Bioinformatics. Vol. 8, Issue 2, pp.29-35.

5. Bryndin E.G. Putmakov A.N. (2019) Frequency color visualization of a condition of the person according to spectral analysis of biofield and biodiagnostics. Journal of Medical Practice and Review. 3(4) Pages: 505-509.

6. Evgeniy Bryndin, Irina Bryndina. (2019) Supporting Technology of Vigorous Activity by Normalization of Biofield and by Healthy Lifestyle. International Journal of Healthcare and Medical Sciences, Vol. 5, Issue 2. Pages: 1-11.

7. Evgeniy Bryndin, Irina Bryndina. (2019) Technological Diagnostics of Human Condition According to Spectral Analysis of Biofield. Advances in Bioscience and Bioengineering. Volume 7, Issue 3. Pages: 64-68.

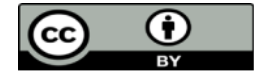

This work is licensed under Creative Commons Attribution 4.0 License

To Submit Your Article Click Here: Submit Manuscript

DOI: $10.31579 /$ jclr.2021/002
Ready to submit your research? Choose Auctores and benefit from:

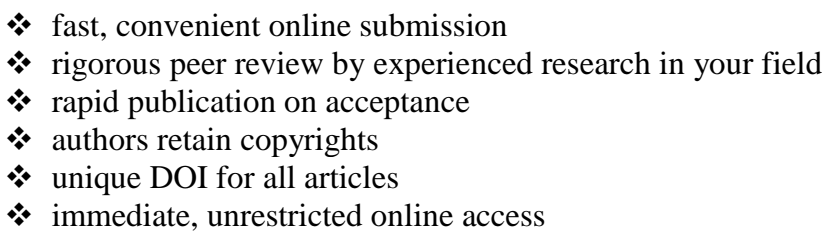

At Auctores, research is always in progress.

Learn more www.auctoresonline.org/journals/journal-of-clinical-andlaboratory-research 